\title{
ESTUDO TERMOGRAVIMÉTRICO E CALORIMÉTRICO DA ALGAROBA
}

\section{Suely Alves da Silva}

Departamento de Química, Universidade Federal Rural de Pernambuco, Recife - PE

Antonio Gouveia Souza", Marta Maria da Conceição e Alisson L. S. Alencar

Departamento de Química, CCEN, Campus I, Universidade Federal da Paraíba, 58059-900 João Pessoa - PB

\section{Shiva Prasad}

Departamento de Engenharia Química, CCT, Campus II, Universidade Federal da Paraíba, Campina Grande - PB

José Marcelino Oliveira Cavalheiro

Departamento de Tecnologia Química e de Alimentos, CT, Campus I, Universidade Federal da Paraíba, João Pessoa - PB

Recebido em 15/2/00; aceito em 13/12/00

\begin{abstract}
CALORIMETRY AND THERMOGRAVIMETRIC STUDY OF ALGAROBA [Prosopis juliflora (SW) D. $C$.]. Humidity and ash content of powder and bran of algaroba pods are important quality parameters for biological control during storage. The studies of humidity and ash content were carried out conventional and thermogravimetric methods. Different values were obtained by the various methods. The thermogravimetric method was faster and required less sample for the humidity and ash analyses of the powder and bran of algaroba pods. The differential scanning calorimetry curves of the powder and bran of algaroba pods, dryed at $55{ }^{\circ} \mathrm{C}$, showed two peaks, one corresponding to the gelatinization of starch and the other to the vaporization of water. The samples dryed at $65,75,85,95$ and $105^{\circ} \mathrm{C}$ showed one peak, corresponding to the vaporization of water.
\end{abstract}

Keywords: thermogravimetry; differential scanning calorimetry; algaroba.

\section{INTRODUÇÃO}

A algaroba [Prosopis juliflora $(S W)$ D. C.], introduzida no Brasil, principalmente no Nordeste há mais de 50 anos, constitui-se numa das raras espécies capazes de possibilitar aos animais e ao próprio homem uma convivência harmoniosa com o fenômeno adverso e periódico das secas. Portanto, a determinação de parâmetros de qualidade como os teores de umidade e cinzas do farelo e do pó da vagem da algaroba, que são utilizados para sua comercialização, é de vital importância para os produtores rurais.

A algaroba é uma espécie vegetal leguminosa, não oleaginosa, nativa das regiões áridas e semi-áridas das Américas, África e Ásia, sendo que nesta última se concentra a maioria das 44 espécies do gênero Prosopis, apresentando portanto, admirável amplitude de adaptação. Esta espécie é utilizada para a produção de madeira, carvão vegetal, estacas, álcool, melaço, alimentação animal e humana, apicultura, reflorestamento, ajardinamento e sombreamento, tornando-se, por conseguinte, uma cultura de valor econômico e social ${ }^{1}$. No Nordeste brasileiro, essa xerófita, introduzida no início da década de 40, com o objetivo de alimentar animais e para ser utilizada em reflorestamento, aparece atualmente como uma possível fonte de alimento alternativo para o homem ${ }^{2}$.

Esta planta produz grande quantidade de vagens de excelente palatibilidade e boa digestibilidade, apresentando em sua composição química de 25-28 \% de glicose, $11-17 \%$ de amido, 7-11\% de proteínas, 14-20\% de ácidos orgânicos, pectinas e demais substâncias. Assim sendo, a algaroba contém, cerca de $43 \%$ de açúcares e amido, constituindo-se num excelente alimento de engorda, além de ser relativamente rico em proteínas. Possuindo um teor de cinzas em aproximadamente $3,75 \%$ e a umidade variando de $16-20 \%$ base úmida ${ }^{3}$

A Análise Térmica constitui um grupo de técnicas de gran-

*e-mail: gouveia@quimica.ufpb.br de interesse na caracterização de alimentos, visto que proporcionam dados relevantes ao processamento industrial de substâncias alimentícias, em um tempo relativamente curto e com certa especificidade quando associada a outras técnicas ${ }^{4,5}$. As potencialidades analíticas da termogravimetria no controle de qualidade dos alimentos têm despertado o interesse dos pesquisadores ultimamente, devido à diminuição do tempo das análises e quantidade de amostra requerida, além de poder ser utilizada na obtenção de parâmetros cinéticos através de métodos de cálculo adequados ${ }^{6}$. Os teores de umidade e cinzas do pó e farelo da vagem da algaroba constituem-se em parâmetros de qualidade. O teor de umidade é utilizado para o controle biológico no armazenamento e a comercialização dos produtos e o teor de cinzas é utilizado para indicar a quantidade de minerais ${ }^{7}$.

O processo de gelatinização ocorre quando o amido é aquecido com água e pode ser medido pela calorimetria exploratória diferencial (DSC). A gelatinização ocorre a uma dada temperatura dentro de uma faixa de $50-70{ }^{\circ} \mathrm{C}$, dependendo da variedade do amido e da sua origem, sendo definida como um rearranjo molecular. A gelatinização do amido apresenta mudança irreversíveis nas suas propriedades, tais como: inchamento dos grânulos, derretimento (fusão) dos cristais iniciais, perda de birrefringência e solubilização do amido ${ }^{8}$.

Este trabalho consistiu em determinar, em amostras submetidas às temperaturas de secagem de 55, 65, 75, 85, $95 \mathrm{e}$ $105{ }^{\circ} \mathrm{C}$, o teor de umidade e cinzas da vagem da algaroba (pó e farelo), por meio de métodos convencional (estufa e mufla), balança de umidade (radiação infravermelho) e termogravimétrico, visando a comparação entre os métodos e com o objetivo de estudar a aplicabilidade da análise térmica nestes estudos, tendo em vista as várias vantagens desta técnica, tais como: diminui a quantidade de amostra e o tempo de análise, evita erros cometidos pela manipulação das amostras, determina simultaneamente teor de umidade e cinzas e possibilita a determinação de parâmetros cinéticos. Além disso, foi estudada a temperatura de gelatinização do amido da algaroba. 


\section{PARTE EXPERIMENTAL}

As amostras das vagens de algaroba foram coletadas na Unidade de Beneficiamento de Vagens de Algaroba para alimentação animal, localizada na Fazenda São Bento, município de Coxixola, Paraíba. As amostras foram submetidas à secagem em estufa de esterilização e secagem, marca OLIDEF CZ, às temperaturas de $55,65,75,85,95$ e $105^{\circ} \mathrm{C}$. Foram submetidas à moagem em moinho de navalha, marca MARCONI, obtendo-se os dois produtos da vagem da algaroba: o pó correspondente ao produto da moagem e o farelo correspondente ao resíduo (o que ficou retido na peneira do moinho). Em seguida os produtos foram tamisados em peneiras, marca GRANUTEST, de abertura $0,250 \mathrm{~mm}$, correspondente a mesh 60 , que foi a granulometria usada nos métodos de análise térmica e convencional, com a finalidade de uniformizar a granulometria das amostras.

As análises convencionais em estufas foram realizadas segundo as Normas Analíticas do Instituto Adolfo Lutz ${ }^{9}$, com pesagem de $5 \mathrm{~g}$ de cada amostra, em cadinho de porcelana, utilizando-se uma balança analítica, marca SHIMADZU, LIBROR AEL-40 SM.

As análises de umidade foram realizadas por calor seco em uma estufa de esterilização e secagem, marca OLIDEF CZ, com temperatura de $105{ }^{\circ} \mathrm{C}$ até peso constante, durante cerca de 4 horas. Em seguida, as amostras foram resfriadas em dessecador e pesadas.

As análises de umidade por radiação infravermelho foram obtidas em uma balança, marca OHAUS, modelo MB200, utilizando-se aproximadamente $10 \mathrm{~g}$ das amostras a uma temperatura constante de $105{ }^{\circ} \mathrm{C}$.

Nas análises de cinzas, as amostras foram carbonizadas em bico de Bunsen, em seguida incineradas em uma mufla, marca QUIMIS, a $600{ }^{\circ} \mathrm{C}$ por um período de 6 horas e depois foram resfriadas em dessecador e pesadas.

As curvas termogravimétricas foram obtidas em uma termobalança, marca SHIMADZU, modelo TGA-50, em atmosfera de ar com vazão constante de $20 \mathrm{~mL} \mathrm{~min}^{-1}$, utilizando-se uma célula de alumina e razão de aquecimento de $10{ }^{\circ} \mathrm{C} \mathrm{min}{ }^{-1}$. Foram tomadas amostras com massa variando entre 10,0 e 10,5 $\mathrm{mg}$, e procedeu-se a varredura da temperatura até $900{ }^{\circ} \mathrm{C}$, permanecendo nesta temperatura por $20 \mathrm{~min}$.

As curvas DSC foram obtidas em um calorímetro exploratório diferencial, marca SHIMADZU, modelo DSC-50, numa faixa de temperatura de $25-200{ }^{\circ} \mathrm{C}$, usando uma célula de alumínio, com razão de aquecimento de $10{ }^{\circ} \mathrm{C} \mathrm{min}^{-1}$, em atmosfera de nitrogênio, com vazão de $50 \mathrm{~mL} \mathrm{~min}^{-1}$, de onde se obteve as curvas de gelatinização do amido e da vaporização da água (umidade), com as respectivas entalpias. Foram preparadas soluções $10 \%$ (massa/massa $)^{10}$ das amostras, para serem analisadas no DSC. Pois, quando uma amostra que contém amido é aquecida com água, observa-se a gelatinização.

Os valores percentuais de umidade e cinzas, obtidos pelo método convencional, foram resultados de três determinações para cada amostra, e em seguida foi efetuada a média destas determinações.

No método termogravimétrico, os percentuais de umidade e cinzas foram resultados de três determinações para cada amostra, em seguida foi efetuada a média destas determinações obtidas diretamente das curvas termogravimétricas, após as mesmas terem sido tratadas no software TASYS. Para determinar o teor de umidade realizou-se o seguinte tratamento das curvas TG: aplica-se a derivada primeira, retira-se as interferências que aparecerem na curva e amplia-se a visualização do intervalo correspondente à perda de água das amostras e onde a curva fica estabilizada, para determinar o início e o final da decomposição térmica de forma mais precisa. Em seguida marca-se o início e o final da derivada, analisa-se e obtém-se o teor de umidade (\%) com suas temperaturas correspondentes. Em relação ao teor de cinzas não se aplica o método da derivada, o valor é obtido diretamente no eixo das ordenadas correspondente ao final do processo de perda de massa, obtendo-se o teor de cinzas (\%) e sua temperatura correspondente.

\section{RESULTADOS E DISCUSSÃO}

Em relação aos teores de umidade e cinzas da algaroba citados anteriormente, respectivamente de $16-20 \%$ e 3,75\%, foram obtidos da vagem de algaroba natural, sem passar por nenhum tratamento térmico, neste trabalho a vagem sofreu um tratamento térmico nas temperaturas de 55, 65, 76, 85, 95 e $105{ }^{\circ} \mathrm{C}$, em seguida a vagem foi triturada obtendo-se o pó e o farelo, para depois serem determinados os teores de umidade e cinzas.

A Tabela 1, apresenta os valores dos percentuais de umidade e cinzas do pó e farelo da algaroba, obtidos pelos métodos convencional, termogravimétrico e por radiação infravermelho (umidade). De um modo geral, os valores para o teor de umidade obtidos pelos métodos termogravimétrico e radiação infravermelho, e os valores para o teor de cinzas obtidos pelo método termogravimétrico são bem correlacionados com os valores obtidos pelo método convencional, para as duas amostras estudadas nas diversas temperaturas de secagem. Em relação ao desvio padrão dos teores de umidade e cinzas do pó e farelo da vagem da algaroba, obtidos nos métodos convencional, termogravimétrico e radiação infravermelho, observa-se que o método termogravimétrico apresentou os menores desvios padrão, sugerindo este como sendo o método mais preciso.

Algumas discordâncias observadas no método termogravimétrico ocorrem, provavelmente, devido a heterogeneidade do farelo (casca, semente, fibras) e também deve estar relacionada,

Tabela 1. Percentuais de umidade e cinzas do pó e farelo da vagem de algaroba, obtidos pelos métodos estufa e mufla (conv.), termogravimétrico (TG) e radiação infravermelho (IV), com seus respectivos desvios-padrão.

\begin{tabular}{ccccccc}
\hline $\begin{array}{c}\text { Temp. } \\
\text { Secagem }\end{array}$ & Amostras & $\begin{array}{c}\text { Umidade } \\
\text { Conv. / } \%\end{array}$ & $\begin{array}{c}\text { Umidade } \\
\text { TG / \% }\end{array}$ & $\begin{array}{c}\text { Umidade } \\
\text { IV / \% }\end{array}$ & $\begin{array}{c}\text { Cinzas } \\
\text { Conv. / \% }\end{array}$ & $\begin{array}{c}\text { Cinzas } \\
\text { TG / \% }\end{array}$ \\
\hline $55{ }^{\circ} \mathrm{C}$ & Pó & $4,130 \pm 0,119$ & $4,543 \pm 0,002$ & $4,000 \pm 0,432$ & $3,580 \pm 0,065$ & $3,180 \pm 0,064$ \\
& Farelo & $4,490 \pm 0,242$ & $3,684 \pm 0,003$ & $5,100 \pm 0,306$ & $2,980 \pm 0,017$ & $2,720 \pm 0,007$ \\
$65{ }^{\circ} \mathrm{C}$ & Pó & $4,120 \pm 0,080$ & $4,432 \pm 0,009$ & $3,900 \pm 0,509$ & $3,490 \pm 0,011$ & $3,500 \pm 0,010$ \\
& Farelo & $3,320 \pm 0,087$ & $3,092 \pm 0,004$ & $3,200 \pm 0,277$ & $3,140 \pm 0,052$ & $2,470 \pm 0,050$ \\
$75{ }^{\circ} \mathrm{C}$ & Pó & $4,014 \pm 0,003$ & $4,427 \pm 0,002$ & $3,870 \pm 0,537$ & $3,340 \pm 0,015$ & $2,480 \pm 0,010$ \\
& Farelo & $3,150 \pm 0,050$ & $3,090 \pm 0,003$ & $3,100 \pm 0,242$ & $3,420 \pm 0,020$ & $2,720 \pm 0,005$ \\
$85{ }^{\circ} \mathrm{C}$ & Pó & $2,310 \pm 0,011$ & $2,259 \pm 0,008$ & $2,400 \pm 0,272$ & $3,360 \pm 0,069$ & $2,330 \pm 0,002$ \\
& Farelo & $2,130 \pm 0,150$ & $2,891 \pm 0,007$ & $2,800 \pm 0,270$ & $3,150 \pm 0,043$ & $2,120 \pm 0,001$ \\
$95{ }^{\circ} \mathrm{C}$ & Pó & $1,530 \pm 0,046$ & $1,735 \pm 0,035$ & $1,800 \pm 0,171$ & $3,450 \pm 0,064$ & $1,410 \pm 0,030$ \\
& Farelo & $1,650 \pm 0,030$ & $2,693 \pm 0,002$ & $1,600 \pm 0,112$ & $3,130 \pm 0,011$ & $1,770 \pm 0,002$ \\
$105{ }^{\circ} \mathrm{C}$ & Pó & $0,990 \pm 0,050$ & $1,063 \pm 0,032$ & $1,100 \pm 0,106$ & $3,570 \pm 0,061$ & $2,120 \pm 0,040$ \\
& Farelo & $1,350 \pm 0,030$ & $2,682 \pm 0,001$ & $1,500 \pm 0,117$ & $3,090 \pm 0,011$ & $2,330 \pm 0,006$ \\
\hline
\end{tabular}


tanto para o farelo como para o pó, com a massa das amostras usadas nas análises, que variou entre 10,0 e 10,5 mg, além da diferença de massa entre as técnicas, pois na análise convencional utiliza-se em torno de $5,0 \mathrm{~g}$, enquanto que, na análise termogravimétrica utiliza-se em torno de $10,0 \mathrm{mg}$. Este fato também deve estar relacionado, provavelmente, devido a temperatura de varredura das amostras, que no método termogravimétrico estende-se até $900{ }^{\circ} \mathrm{C}$ e no método convencional até $600{ }^{\circ} \mathrm{C}$. Portanto a $600{ }^{\circ} \mathrm{C}$ resta ainda os sulfatos, carbonatos, fosfatos, silicatos (resíduos minerais) e a $900{ }^{\circ} \mathrm{C}$ essas substâncias são decompostas nos seus respectivos óxidos, ocorrendo uma diminuição dos teores de cinzas obtidos pela termogravimetria.

A Tabela 2 apresenta as temperaturas de transições do amido, do pó e farelo da vagem da algaroba, com suas respectivas variações de entalpia, determinadas a partir das áreas dos picos correspondentes à gelatinização e a vaporização da água (umidade), analisados no calorímetro exploratório diferencial. A temperatura de gelatinização $\left(T_{1}\right)$ está dentro do intervalo citado na literatura. Em relação a temperatura de vaporização da água $\left(\mathrm{T}_{2}\right)$ comparando os valores do pó e farelo a cada temperatura de secagem, observa-se que os valores de $T_{2}$ para o farelo apresentaram-se maiores, devido a característica heterogênea da amostra. Em relação a entalpia de vaporização da água $\left(\Delta \mathrm{H}_{2}\right)$ observou-se que os valores aumentam de acordo com o aumento da temperatura de secagem, provavelmente, devido a amostra encontrar-se mais desidratada.

Pode-se observar nas Figuras 1 e 2, que o pico da gelatinização aparece apenas na amostra seca a $55^{\circ} \mathrm{C}$, mesmo com este aquecimento prévio, não se alterou a estrutura do amido. Nesta curva observa-se dois picos, o primeiro é referente à gelatinização e o segundo à vaporização da água (umidade). $\mathrm{O}$ pico da gelatinização não aparece nas demais curvas, porque as amostras sofreram aquecimento prévio, já possuindo portanto, devido à secagem, a estrutura do amido modificada. Nas amostras com temperaturas de secagem $65,75,85,95$ e $105{ }^{\circ} \mathrm{C}$ observa-se apenas um pico, referente à vaporização da água (umidade) $)^{11}$.

Tabela 2. Temperaturas de gelatinização do amido, da vaporização da água e as respectivas variações de entalpia do pó e farelo da vagem de algaroba.

\begin{tabular}{|c|c|c|c|c|c|}
\hline Temp. Secagem & Amostras & $\mathrm{T}_{1} /{ }^{\circ} \mathrm{C}$ & $\Delta \mathrm{H}_{1} / \mathrm{Jg}^{-1}$ & $\mathrm{~T}_{2} /{ }^{\circ} \mathrm{C}$ & $\Delta \mathrm{H}_{2} / \mathrm{Jg}^{-1}$ \\
\hline \multirow[t]{2}{*}{$55^{\circ} \mathrm{C}$} & Pó & 60,76 & 357,58 & 107,68 & 380,04 \\
\hline & Farelo & 54,00 & 487,27 & 124,28 & 346,17 \\
\hline \multirow[t]{2}{*}{$65^{\circ} \mathrm{C}$} & Pó & - & - & 98,93 & 570,01 \\
\hline & Farelo & - & - & 109,51 & 1130,0 \\
\hline \multirow[t]{2}{*}{$75^{\circ} \mathrm{C}$} & Pó & - & - & 115,23 & 632,54 \\
\hline & Farelo & - & - & 117,46 & 1191,8 \\
\hline \multirow[t]{2}{*}{$85^{\circ} \mathrm{C}$} & Pó & - & - & 108,81 & 799,87 \\
\hline & Farelo & - & - & 131,17 & 1242,8 \\
\hline \multirow[t]{2}{*}{$95^{\circ} \mathrm{C}$} & Pó & - & - & 88,03 & 1040,0 \\
\hline & Farelo & - & - & 89,88 & 1260,0 \\
\hline \multirow[t]{2}{*}{$105^{\circ} \mathrm{C}$} & Pó & - & - & 117,47 & 1074,0 \\
\hline & Farelo & - & - & 122,09 & 1327,0 \\
\hline
\end{tabular}

$\mathrm{T}_{1}=$ Temperatura de gelatinização do amido; $\mathrm{T}_{2}=$ Temperatura de vaporização da água; $\Delta \mathrm{H}_{1}=$ Variação de entalpia de gelatinização; $\Delta \mathrm{H}_{2}=$ Variação de entalpia de vaporização.

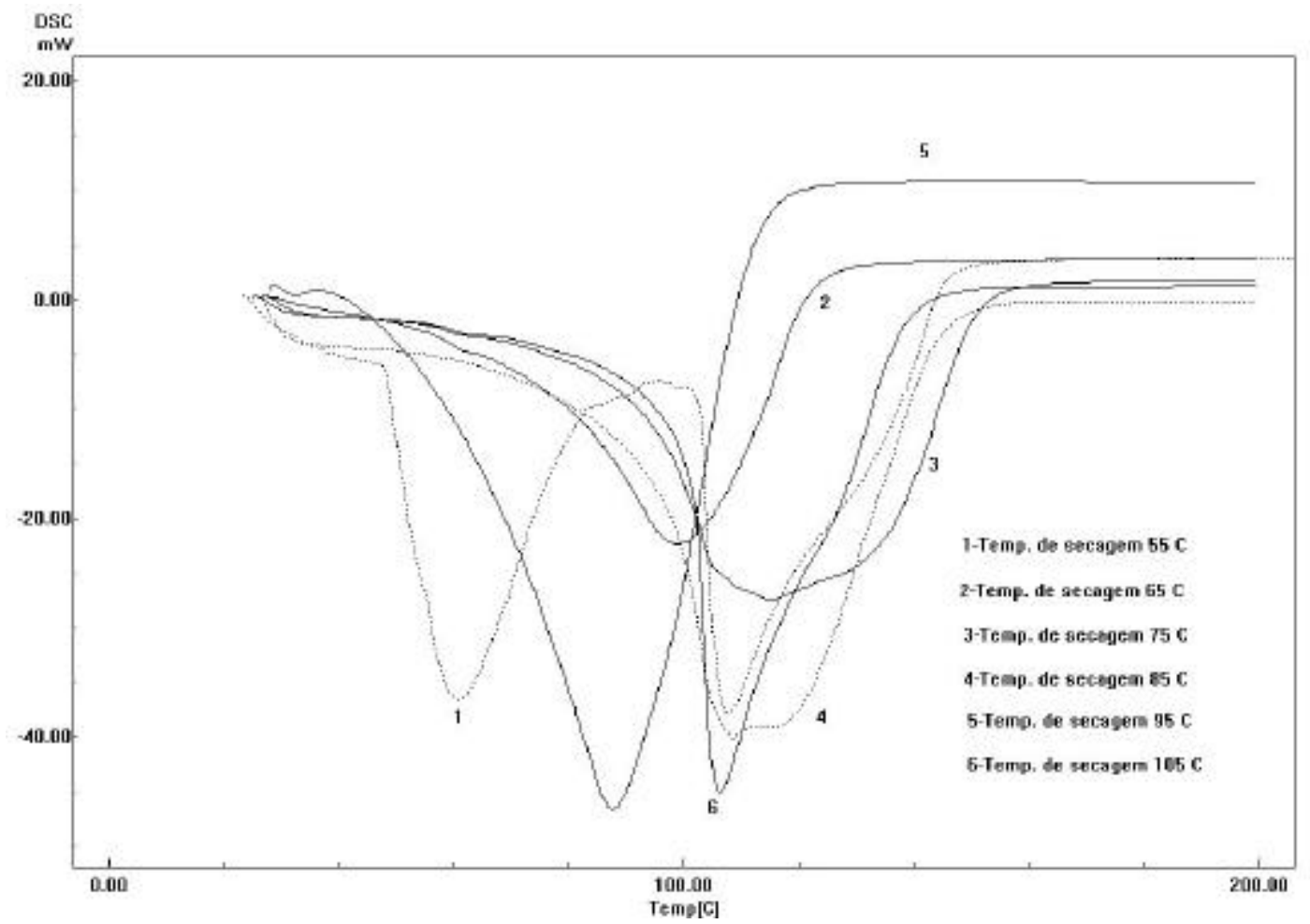

Figura 1. Curvas DSC da gelatinização do amido do pó da vagem de algaroba obtidas a diversas temperaturas de secagem. 


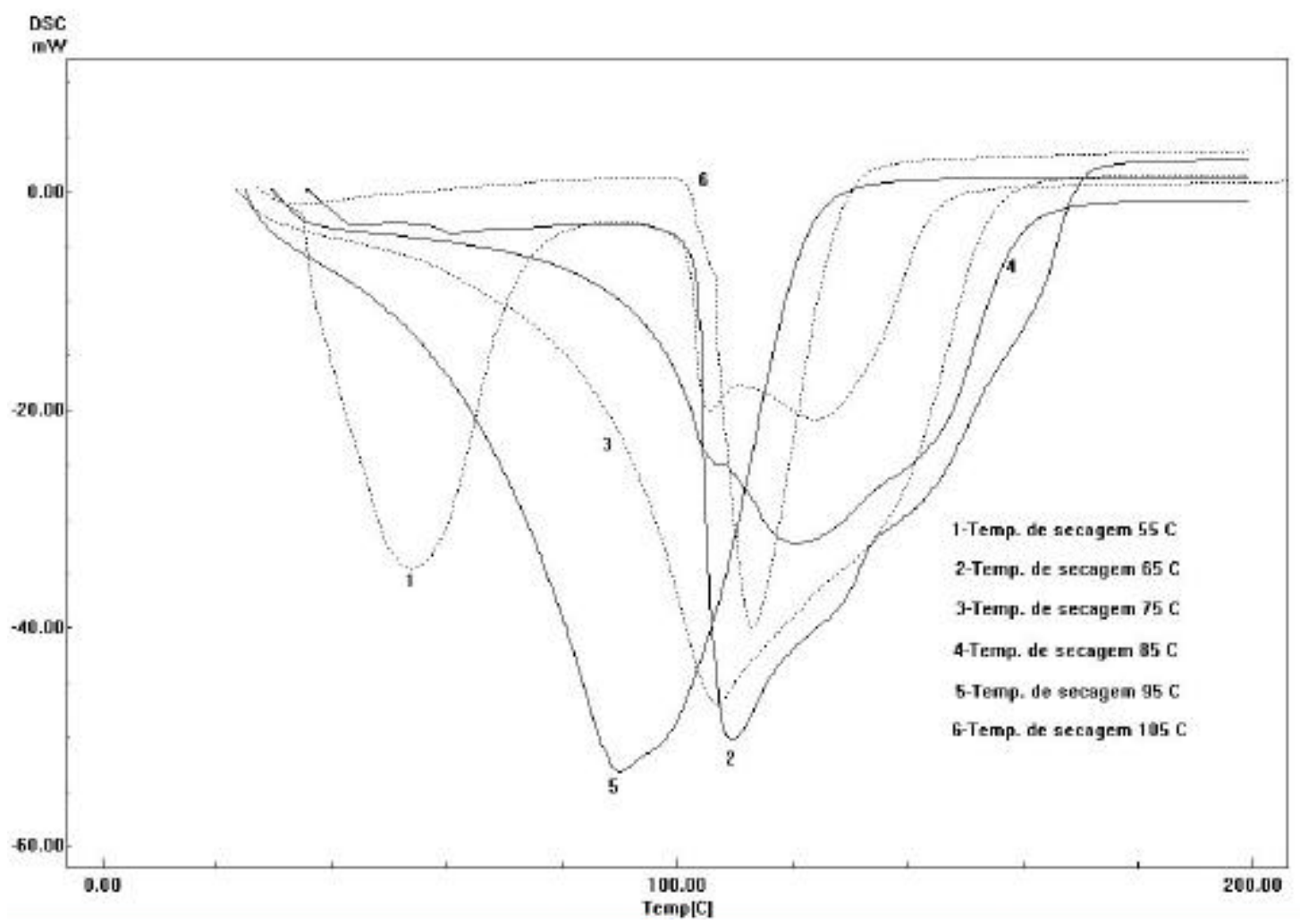

Figura 2. Curvas DSC da gelatinização do amido do farelo da vagem de algaroba obtidas a diversas temperaturas de secagem.

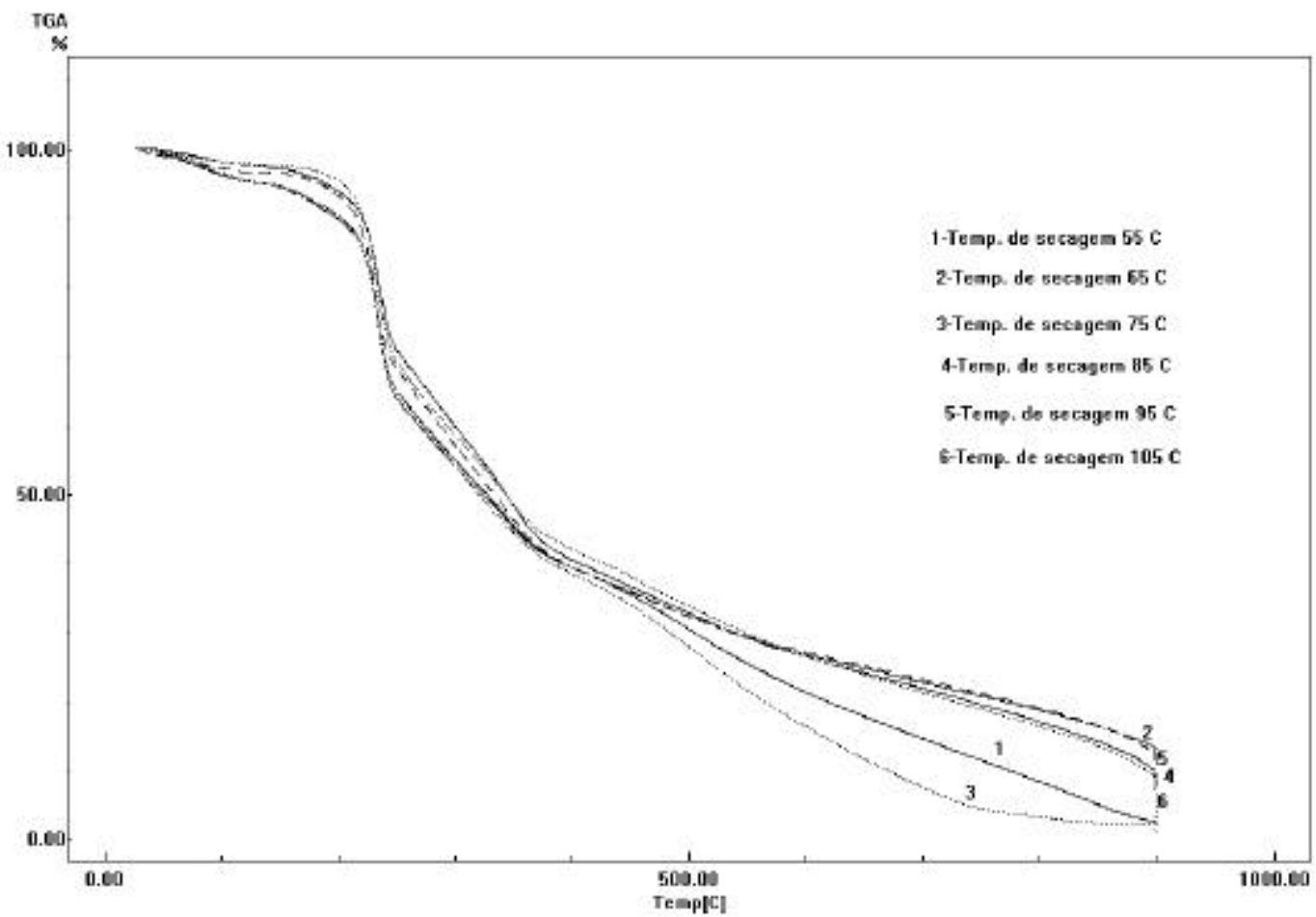

Figura 3. Curvas TG do pó da vagem de algaroba obtidas a diferentes temperaturas de secagem 


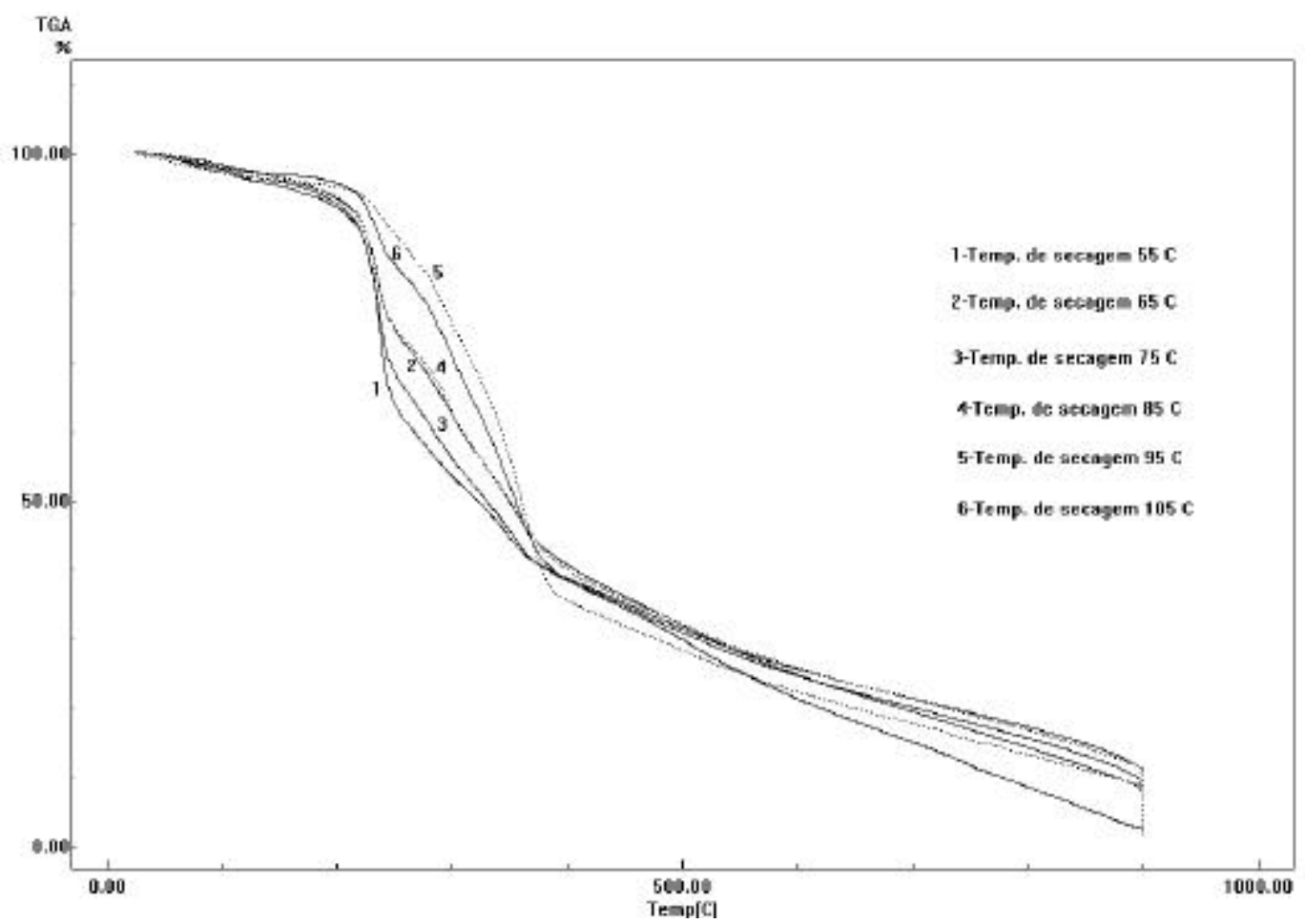

Figura 4. Curvas TG do farelo da vagem de algaroba obtidas a diferentes temperaturas de secagem.

As Figuras 3 e 4, apresentam as curvas TG da decomposição térmica do pó e farelo da vagem de algaroba, nas temperaturas de secagem a $55,65,75,85,95$ e $105{ }^{\circ} \mathrm{C}$. A primeira etapa foi atribuída à desidratação das amostras, as demais etapas foram atribuídas à decomposição térmica dos carboidratos e proteínas presentes nas amostras.

\section{CONCLUSÕES}

Os resultados termoanalíticos do teor de umidade e cinzas do pó e farelo da vagem da algaroba obtidos pelos métodos convencionais (estufa e mufla), termogravimétrico e radiação infravermelho foram satisfatórios para as temperaturas de secagem estudadas.

O método termogravimétrico na determinação do teor de umidade e cinzas das amostras estudadas apresenta valores próximos aos obtidos por um método tradicionalmente aceito e apresenta as seguintes vantagens: permite obter este valor em um tempo bem menor, utiliza uma quantidade de amostra pequena e o registro da perda de massa ocorre de maneira automatizada, evitando os erros provocados por manipulações excessivas do operador com a amostra.

Os dados calorimétricos do pó e farelo da vagem de algaroba, obtidos na temperatura de secagem a $55{ }^{\circ} \mathrm{C}$, identificaram a transição referente a entalpia de gelatinização do amido. Não foi detectada a entalpia de gelatinização do amido, no pó e farelo da vagem de algaroba, obtidas nas temperaturas de secagem a $65,75,85,95$ e $105{ }^{\circ} \mathrm{C}$.

\section{AGRADECIMENTOS}

Os autores agradecem ao CNPq pelo auxílio concedido.

\section{REFERÊNCIAS}

1. Perez, S. C. J. A.; Morais, J. A. P. V.; Pesq. Agrop. Bras., Brasília, 1991, 26, 1493.

2. Silva, J. B.; Dissertação de Mestrado, CT, UFPB, João Pessoa, Paraíba, 1993.

3. Figueiredo, A. A.; Rev. Ass. Bras. Alg. 1987, 1.

4. Carrasco, F.; Thermochim. Acta 1993, 213, 115.

5. Keattch, C. J.; Dollimore, D.; An Introduction to Thermogravimetry, Second Edition, Heyden, London, 1975.

6. Wendlandt, W. W.; Thermal Methods of Analysis, Interscience Publishers, New York, 1964.

7. Accquistucci, R.; Bucci, R.; Magri, A. D.; Magri, A. L.; Thermochim. Acta 1991, 188, 51.

8. Raemy, A.; Lambelet, P.; Thermochim. Acta 1991, $193,417$.

9. Lutz, A.; Normas Analíticas do Instituto Adolfo Lutz, São Paulo, 1985; p 21.

10. Biliaderis, C. G.; Maurice, T. J.; Vose, J. R.; J. Food Science 1980, 45, 1669.

11. Silva, S. A.; Conceição, M. M.; Souza, A. G.; Macêdo, R. O.; Thermochim. Acta 1999, 328, 177. 